\title{
Job Burnout and Job Satisfaction in the Banking Sector; the Perceptions of Bank Employees in Greece
}

\author{
Maria Gidou ${ }^{\mathrm{a}}$, George N. Paltayian ${ }^{\mathrm{b}}$ and Dimitris Gavalas ${ }^{\mathrm{c}, \mathrm{d}, *}$ \\ ${ }^{a}$ School of Social Sciences, Hellenic Open University, Patras, Greece. \\ ${ }^{b}$ Department of Business Administration, University of Macedonia, Thessaloniki, Greece. \\ ${ }^{c}$ Department of Shipping Trade and Transport, University of the Aegean, Chios, Greece. \\ ${ }^{d}$ Audencia Business School, Nantes, France.
}

\begin{abstract}
Job satisfaction and job burnout are two concepts strongly mentioned in the literature, having confirmed a negative correlation between job satisfaction and job burnout. In the banking sector, research shows that job burnout is a frequent occurrence, highlighting the negative correlation between job burnout of bank employees and their job satisfaction. This paper explores the perceptions of bank employees in Greece regarding their level of job satisfaction and job burnout. The possible correlations between these two variables and the possible impact of demographics are also studied. The results are believed to offer significant implications for future research and practice in the Greek banking sector that has received a number of changes such as procedures from acquisitions and mergers and voluntary withdrawals in the human resource area, trying to find a way out of the consequences of the crisis.
\end{abstract}

Keywords: Job satisfaction, professional burnout, banking industry.

\section{INTRODUCTION}

The banking sector seems to enter a transformative environment, since the 2007-2008 financial crisis, where a new wave of acquisitions and mergers take place last years in the banking industry. Changes in the banking industry affect consumer trends in banking technologies, competition, and regulatory changes. According to the research of Abate et al (2018), the sector is characterized by technological advancements in banking services, while also banks seem to change the way they do business, by adopting innovation in the work place. These trends contribute to a more efficiently oriented workplace, but reduction in the number of manpower is obvious, especially with reference to in-person facilities. All the above affect job satisfaction and turnover intention, as for example the findings of the research of Abate et al (2018) reveal, showing that satisfied employees report less job burnout and are more likely to remain in their job.

In such a changing environment, critical social, economic, and cultural transformations take place around the world. The crisis has affected many aspects of the global economy and business administrations often turn to changes in human resources management strategies in order to achieve greater efficiency. These strategies are sometimes accompanied by positive and sometimes negative perceptions of employees, about management's incentives for human resources strategies. Positive employee perceptions have been associated

*Address correspondence to this author at Department of Shipping Trade and Transport, University of the Aegean;

E-mail: dgaval@aegean.gr with higher levels of job satisfaction and general well-being as well as with lower levels of anxiety.

The concept of job satisfaction has been extensively studied by scholars, stating that it is a universal, multidimensional concept, defined by both internal and external factors (Judge et al., 2001). According to Christen at al. (2006), Cohrs at al. (2006) and Rayton (2006), the importance of job satisfaction has emerged, as it has a positive effect on the personal wellbeing of the employee and on the organizational efficiency of the company. As mentioned in Lim (2008), job satisfaction can be defined as the consequence of a person's experience regarding work and it appears to be related to his mental health, while it is also related to increased productivity and level of turnover. Spector (2000) states that job satisfaction can be categorized as internal (which stems from work itself) and as external (which stems from the working environment).

Moreover, burnout syndrome is an important issue in modern working environments, characterized by significant prevalence in recent decades (Maslach et al., 2001). It was initially oriented by Freudenberger (1974) as a state of emotional exhaustion, due to employee interactions with other people. The syndrome is more common among people whose work includes intensive interactions such as nurses, doctors, psychologists, social workers, teachers, and banking employees (Jackson et al., 1986). According to Maslach and Jackson (1981), burnout is a syndrome bounded by three elements (Cañadas-De la Fuente et al., 2015): emotional exhaustion, depersonalization, and reduced personal achievement. It occurs in the workplace and it is caused by chronic stress. Vargas et al. (2014) and Pereda-Torales et al. (2009) support that 
the factors enhancing burnout are related to both personal variables (socio-demographic and personality elements) as well as organizational factors (relating to the working environment), (Aydemi and Icelli, 2013). The main cause of the syndrome is the reduction of the quality of working life. The symptoms of the syndrome vary to physical, psychological, emotional, and behavioral and appear gradually, becoming more intense as time goes on (SSQ Financial Group, 2013). The syndrome leads not only to health problems, but also to social and economic costs (Maslach et al., 2001).

Due to the rapid changes in the organization and structure of banking sectors globally, both concepts (job satisfaction and burnout) are mentionable issues in banking institutions. With reference to Greece, changes in the banking map of the country have left their mark on working conditions and the daily lives of workers, so a significant impact has been generated on both the organization aspect of banks and on the health of their workforce. Banking sector is an area of the utmost importance in the global economy and it is obvious that it must have a satisfied and healthy workforce in order to have a competitive position and offer excellent banking service to the customer (Giorgi et al., 2017). All the above highlights the importance of investigating the present issue. It makes it even more crucial since Greek banking industry has underreceived several changes such as acquisitions and mergers and voluntary withdrawals and is trying to find a way out of the consequences of the crisis. In such an environment, it is important for a bank employee to experience reduced stress and a lower risk of burnout.

Job satisfaction and job burnout are two concepts strongly mentioned in the burnout and job satisfaction, and sometimes they do not. So, under the above framework, the purpose of the paper is to examine the level of job satisfaction and job burnout, by investigating the case of the Greek banking sector The correlations between these two variables and the possible impact of demographics will be also explored, reinforcing our contribution to the existing literature. In the banking sector, research shows that job burnout is a frequent occurrence, highlighting the negative correlation between job burnout of bank employees and their job satisfaction. With reference to demographics, sometimes they differentiate the levels of job between these two variables and the possible impact of demographics are believed to offer significant implications for future research and practice in the Greek sector that has received a number of changes, such as procedures from acquisitions and mergers and voluntary withdrawals, trying to find a way out of the consequences of the crisis.

The rest of the paper is organized as follows: The following section discusses previous research as the starting point of our proposed work. Section 3 presents the methodological framework. Section 4 illustrates the implementation and the results of the framework which were applied in banking sector. The last section summarizes key findings, presents limitations and offers suggestions for further research.

\section{LITERATURE REVIEW}

The concept of job satisfaction has been widely studied in the literature, with most scholars reporting that it is a universal, multidimensional concept, defined by both internal and external factors. In more detail, job satisfaction is influenced by the conditions of the working environment, earnings, level of stress, intensity of work, leadership, but also by the characteristics of the employee's personality and the general satisfaction he/she feels from his/her life (Judge et al., 2001). As it is stated to George and Zakkariya (2015), job stress can be defined as an employee's awareness or feeling of personal dysfunction, because of perceived conditions or happenings in the workplace. Lawler (1990) orients job satisfaction as people's feelings about the rewards they have received on the job. In a similar way, Spector (1997) described job satisfaction as how people feel about their jobs and different aspects of their jobs. Moreover, job satisfaction is defined as one's emotional response to a job that results from the person's expectations of the job and the reality of the job situation. Job satisfaction is an important matter for service industry employees because the satisfied staff is more likely to make consumers feel also satisfied by the service they get (Hsiao and Kohnke, 1998).

Job burnout syndrome has its explanatory basis in chronic stress from work and is defined by three elements: emotional exhaustion, depersonization and reduced personal integration (Maslach and Jackson, 1981). Job burnout is intensified by both personal and organizational components. The main cause of this is the reduction in the quality of life at work. Symptoms of the syndrome are various and become more intense as time passes. They refer to physical, psychological, but also emotional symptoms and effects on the behavior. People with job burnout feel extremely tired, feel alienated from their work, experience reduced proficiency and depressed mood, increased irritability, inability to relax, sleep disturbance, physical discomforts such as muscle aches, headaches, gastrointestinal problems, concentration, and memory problems. Job burnout leads not only to deteriorating health, but also to social and economic costs (Maslach et al., 2001). In terms of demographics, there are significant differences between men and women but also in relation to marital status and in relation to work levels in an organization (Aydemi and Icelli, 2013).

Several studies have identified a variety of personal, interpersonal, and organizational factors associated with job satisfaction, work stress, and burnout syndrome, confirming a negative correlation between job satisfaction and job burnout (Schaufeli and Enzmann, 1998; Nirel, et al., 2004; Ozyurt et al., 2006). Low job satisfaction can lead to more frequent absences from work, which can affect mental and physical health, productivity, behavior, and high levels of stress. The negative correlation between job satisfaction and job burnout in the banking sector is supported by several studies like these of Abate et al. (2018), Gupta et al. (2018), Giorgi et al. (2017), George and Zakkariya (2015), Belias and Koustelios (2014), Devi and Nagini (2013), Al-Kahtani and Allam (2013), Mantelou et al. (2010).

In the banking sector, research shows that job satisfaction has been studied in parallel with industrial relations, but also with reference to organizational hierarchy, financial rewards, and the type of banking institution, public or private (Singh and Kaur, 2009; Sowmya and Panchanatham, 2011). Crossman and Abou-Zaki (2003) state in their research that job satisfaction depends on the different aspects of work. Re- 
garding burnout, they support that it is a common phenomenon in highly demanding working environments, where people work under great pressure (such as the banking sector). People who feel a strong feeling of work-related stress often experience emotional exhaustion and disappointment (Shaw et al., 2000), reaching to job burnout, with serious consequences - physical, social, mental, and emotional.

Various studies have investigated the work-related stress in the banking sector, the job burnout of bank employees and their level of job satisfaction, highlighting the negative correlation between job satisfaction and job burnout (Giorgi et al., 2017). According to the study of Belias and Koustelios (2014), which was based on a quantitative survey of a sample of 230 bank employees in Greece, it was found that job satisfaction experienced by employees was at quite high levels. Moreover, there was a strong negative correlation between the two variables: the burnout of bank employees and their job satisfaction. Similarly, Gupta et al. (2018) studied the concept of burnout and its relationship to job satisfaction in a sample of 251 banking workers in India. According to the researchers, emotional exhaustion had a significant negative impact on employee satisfaction. The negative relationship between job satisfaction and burnout was also highlighted by the survey of Devi and Nagini (2013) in a sample of 103 employees at private banks, as well as by the survey of Ismail et al. (2013) in a sample of 209 financial sector workers in Johannesburg. Additionally, Abate et al. (2018) also revealed the negative correlation between job satisfaction and job burnout, by studying a sample of 100 retail banking employees in the United States, via an online survey. Researchers found statistically significant relationships between job burnout and turnover intention and between job satisfaction and turnover intention. These findings show that satisfied employees report less job burnout and are more likely to remain in their job.

According to demographics, and with reference to the research of Al-Kahtani and Allam (2013), that was conducted in a sample of 274 bank workers in Saudi Arabia, it was found that men had a higher level of burnout than female employees, while female bank employees were found significantly more satisfied with their work than their male colleagues. Literature also states that job satisfaction and jobrelated stress vary among employees of different banking sectors. This outcome is supported by the research of George and Zakkariya (2015), who examined via a questionnaire a sample of 337 employees from various banks of the private sector, public sector, and new generation banks. Their analysis revealed that employees of different sectors of bank had different level of job satisfaction and job-related stress. In fact, it was found that employees working in public sector banks have lower job-related stress when compared to private sector banks and new generation banks; and higher job satisfaction when compared to new generation banks. Mantelou et al. (2010) also examined the job burnout syndrome in Greek bank clerks, the correlation between job burnout and job satisfaction and the impact of demographic characteristics of the sample. Their research was based on questionnaires and revealed that job satisfaction was correlated with some dimensions of burnout. Further, all demographic factors, except for gender, were correlated to job burnout dimensions.

\section{METHODOLOGICAL ISSUES}

Regarding the research process, the first step was related to the conduction of the literature review part. This phase included the search on the factors of interest regarding the research investigation and the formulation of the research hypotheses, as Table 1 shows:

Table 1: Research hypotheses

\begin{tabular}{ll}
\hline No & Hypothesis \\
\hline 1 & Job satisfaction is related to emotional exhaustion, depersonalization, personal \\
& achievement. \\
2 & Job satisfaction is affected by demographics. \\
3 & Emotional exhaustion, depersonalization, and personal achievement are affected by \\
& demographics. \\
\hline
\end{tabular}

A quantitative method was applied in the context of this investigation. The choice of this type of method was based on the fact that the goal was to investigate the possible relationship between two variables, the level of job satisfaction and the job burnout of bank employees, as well as the possible impact of demographics. The choice of quantitative method was also based on the fact that existing surveys most often exploit quantitative research to examine the views of employees on the framework of the examined topic. In addition, the use of quantitative research can provide representative and widely generalized information on the confirmation or non-confirmation of research hypotheses.

The research tool that was used is the questionnaire. Questionnaire is a common research tool in quantitative method (Adams and Cox, 2008). The questionnaire of this research was based on the literature findings and was created on Google Forms. The questionnaire consisted of three parts. The first part included demographic questions. The second part consisted of the scale of job satisfaction of Bhatt (2004), including 10 questions on a Likert scale. The third part included the scale of job burnout (Maslach and Jackson, 1986) with 22 questions on a Likert scale. This questionnaire is the only one that measures all three dimensions of job burnout.

The questionnaire was electronically distributed to the sample of 500 bank employees via email and a number of $\mathrm{N}=300$ employees finally completed the form. During the research process, bank employees were informed about the anonymity and significance of this investigation. The research took place during the period from 11 December 2019 to 9 February 2020 . The analysis and processing of the data was carried out with the SPSS, as it is a useful tool for conducting statistical correlations. Data analysis included descriptive and inferential statistics. Descriptive statistics were performed by using frequency tables, pie charts and bar charts. Inferential statistics were performed by using Pearson Correlation and ttest for two independent samples.

Finally, as about the robustness of the measurement, it refers to the consistency of the measure (Cohen et al., 2007) and it is measured through reliability indexes, like Crobach Alpha (Tavakoll and Dennick, 2011). The allowable values of this reliability index are above 0.7 (Pallant, 2010). Table 2 shows the reliability levels for all groups of questions that measure 
each variable. All variables were found reliable since the value is greater than 0.7 .

Table 2: Crobach Alpha and reliability

\begin{tabular}{lcc}
\hline \multicolumn{1}{c}{ Variable } & Crobach Alpha & Reliability \\
\hline Emotional exhaustion & 0.914 & Confirmed \\
Depersonalization & 0.730 & Confirmed \\
Personal achievement & 0.778 & Confirmed \\
Job satisfaction & 0.819 & Confirmed
\end{tabular}

\section{EMPIRICAL RESULTS}

Data were collected electronically. Their analysis and processing were carried out by using SPSS. The questionnaire was initially distributed on a sample of 500 bank employees; eventually a number of 300 fulfilled the form (60\%). Among the 300 participants, most were women, with diploma degree, having a job position of official, working in a town, being married and having children. In terms of their income, the majority stated they had a fixed income. Most of the employees have a daily contact with the customers and work exclusively inside the bank's store. A voluntary exit program has been proposed for most of the participants. Table 3 shows the profile of the sample that participated in the research.

Table 3: The sample's profile

\begin{tabular}{llll}
\hline Attribute & Frequency & Attribute & Frequency \\
\hline Men & $35 \%$ & Women & $65 \%$ \\
Diploma & $50,4 \%$ & Master & $43.1 \%$ \\
Officials & $67.5 \%$ & Managers & $26 \%$ \\
Directors & $6.5 \%$ & & \\
Town & $66.7 \%$ & Out of town & $33.3 \%$ \\
Having children & $77.2 \%$ & Without children & $22.8 \%$ \\
Married & $76.4 \%$ & Single & $23.6 \%$ \\
Decrease in earnings & $29.3 \%$ & Fixed Earnings & $63.4 \%$ \\
Increase in earnings & $7.3 \%$ & &
\end{tabular}

Among the total number of variables that were studied in order to determine any possible correlation between them and via the Pearson correlation analysis, it was found that work satisfaction and personal achievement are positively related to each other, with moderate intensity $(\mathrm{r}=+0.431$, $\mathrm{p}=0.000<0.05)$. All other correlations among the examined variables were no significant.

Further, an analysis of independent samples (t-test) was carried out to test if there was any statistically significant difference between men and women regarding the examined variables. The homogeneity control of Levene for the case of emotional exhaustion was positive and $\mathrm{p}=0.003<0.05$ (table 4). Thus, it was found that there was a statistically significantly differentiation in levels of emotional exhaustion between men and women. Women experienced greater emotional exhaustion than men. All other tests showed no differences regarding gender.
Table 4: T- test for emotional exhaustion and gender

\begin{tabular}{ll}
\hline Homogeneity control of Levene & Yes $(\mathbf{p}>\mathbf{0 . 0 5})$ \\
\hline Mean of men & 3.36 \\
Mean of women & 4.04 \\
P Value & $0.003<0,05$ \\
Difference & Yes
\end{tabular}

Next it was tested if there was any statistically significant difference in married and single regarding the examined variables. The homogeneity control of Levene for the case of emotional exhaustion was positive and $\mathrm{p}=0.043<0.05$ (Table 5). Thus, it was found that there was a statistically significantly differentiation in levels of emotional exhaustion between married and single. Married people seemed to be more emotionally exhausted than single. All other tests showed no differences regarding marital status.

Table 5: T- test for emotional exhaustion and marital status

\begin{tabular}{ll}
\hline Homogeneity control of Levene & Yes $(\mathbf{p}>\mathbf{0 . 0 5})$ \\
\hline Mean of married & 3.92 \\
Mean of single & 3.42 \\
P Value & $0.043<0,05$ \\
Difference & Yes
\end{tabular}

\section{SUMMARY AND CONCLUSIONS}

From the results it became apparent that when the person feels more satisfied, the feeling of personal achievement becomes greater. So, in this case, the person does not feel high levels of professional burnout. This finding is consistent with previous research which suggests that increased job satisfaction is associated with low job burnout (Giorgi et al., 2017; Belias and Koustelios, 2014; Gupta et al., 2018; Devi and Nagini, 2013; Ismail et al., 2013). Further, it was found that women seemed to feel more emotional exhausted than men. This is opposite with the research of Al-Kahtani \& Allam (2013), who showed that men were found to have higher levels of job burnout than women.

As far as job satisfaction is concerned, this survey did not show any differentiation in relation to demographic. This is opposite to the survey of Al-Kahtani and Allam (2013), who showed that female bank employees were significantly more satisfied with their work compared to their male colleagues.

The contribution of the present research is highlighted through the findings that differ from previous research, which concern: (i) the differentiation of gender and marital status regarding the levels of emotional exhaustion, (ii) the differentiation of age and level of education regarding the levels of burnout, and (iii) the differentiation of demographics regarding the level of job satisfaction. We would consider a limitation of our study the fact that due to the sampling method, the results cannot be generalized; random sampling, covering various geographical areas of Greece, in 
order to test whether the present results are valid in the general population would be another area of for further research.

As for the proposals, focus should be given by managers regarding the fact that women feel more emotionally exhausted than men, as well as regarding the fact that married people feel more emotionally exhausted than single. Based on these, it is suggested to intervene in the groups that show greater emotional exhaustion to be more likely to reduce their levels of emotional exhaustion.

\section{CONFLICT OF INTEREST STATEMENT}

The authors declare that they have no conflict of interest.

\section{REFERENCES}

Abate, J., Schaefer, T., \& Pavone, T. (2018). Understanding generational identity, job burnout, job satisfaction, job tenure and turnover intention. Journal of Organizational Culture, Communications and Conflict, 22(1), pp. 1-12.

Adams, A., \& Cox, A. L. (2008). Questionnaires, in-depth interviews and focus groups. In: Cairns, Paul and Cox, Anna L. eds. Research Methods for Human Computer Interaction. Cambridge, UK: Cambridge University Press, pp. 17-34.

Alarcon, G., Eschleman, K.J., \& Bowling, N.A. (2009). Relationships between personality variables and burnout: a meta-analysis. Work Stress, 23(3), pp. 244-263.

Al-Kahtani, N.S., \& Allam, Z. (2013). A comparative study of job burnout, job involvement, locus of control and job satisfaction among banking employees of kingdom of Saudi Arabia. Life Science Journal, 10(4), pp. 2135-2144.

Al-Turki, H.A. (2010). Saudi Arabian nurses are they prone to burnout syndrome? Saudi Medical Journal, 31(3), pp. 313-316.

Auster, E.R. (2001) Professional women's midcareer satisfaction: towards an explanatory framework. Sex Role, 44(11/12), pp. 719-750

Aydemir, O., \& Icelli, I. (2013). Burnout: risk factors. In: Bahrer-Kohler, S. (Ed.), Burnout for Experts: Prevention in the Context of Living and Working. Springer, New York, NY, pp. 119-143.

Belias, D., \& Koustelios, A. (2014). Job Satisfaction and Job Burnout Among Greek Bank Employees. International Journal of Management, 5, pp. 33-45.

Cañadas-De la Fuente, G., Vargas, C., San Luis, C., García, I.,Cañadas, G., $\&$ de la Fuente, E. (2015). Risk factors and prevalence of burnout syndrome in the nursing profession. International Journal of Nursing Studies, 52(1), pp. 240-249.

Chen, J.C., \& Silverthorne, C. (2008). The impact of locus of control on job stress, job performance and job satisfaction in Taiwan. Leadership and Organization Development Journal, 29(7), pp. 572-82.

Christen, M., Lyer, G., \& Soberman, D. (2006). Job satisfaction, job performance, and Effort: A reexamination using agency theory. Journal of Marketing, 70(1), pp. 137- 150.

Cohen, L., Manion, L., \& Morrison, K. (2007). Research Methods in Education (6th ed.). London: Routledge.

Cohrs, J. C., Abele, A. E., \& Dette, D. A. (2006).Integrating situational and dispositional determinants of job satisfaction: Findings from three samples of professionals. The Journal of Psychology, 140(4), pp. 363-395.

Crossman, A., \& Abou-Zaki, B. (2003).Job satisfaction and employee performance of Lebanese banking staff. Journal of Managerial Psychology, 18(4), pp. 368-376.
Devi, V. R., \& Nagini, A. (2013). Work-life balance and burnout as predictors of job satisfaction in private banking sector. Skyline Business Journal, 9(1), pp. 50-53.

Dugguh, S. (2008). Human resource management, Makurdi: Oracle Press Ltd.

Fetai, B., Abduli, S., \& Qirici, S. (2015). An ordered prohibit model of job satisfaction in the former Yugoslov Republic of Macedonia. Procedia-Social and Behavioral Sciences, 33, pp. 350-357.

Freudenberger, H. (1974). Staff Burnout. Journal of Social Issues, 30, pp. 159-165.

George, E., \& Zakkariya, K.A. (2015). Job related stress and job satisfaction: a comparative study among bank employees. Journal of Management Development, 34(3), pp. 316-329.

Georgellis, Y., Lange, T., \& Tabvuma, V. (2012).The impact of life events on job satisfaction. Journal of Vocational Behavior, 80, pp. 464473 .

Greenberg, J., \& Baron, A. (2000). Behavior in organizations, 7th edn, N.J.: Prentice Hall.

Gupta, B., Mittal, S., \& Mittal, V. (2018). Analyzing The Impact Of Job Burnout On Job Satisfaction - A Study On Indian Bank Employees. Special Issue for International Youth Symposium, 10, pp. 1930 .

Hanaysha, J., \& Tahir, P.R. (2016). Examining the effects of employee empowerment, teamwork and employee training on job satisfaction. Procedia-Social and Behavioral Sciences, 219, pp. 272-282.

Herzberg, F., Mausner, B., \& Snyderman, B. B. (1959). The Motivation to Work. New York: Wiley.

Hsiao, H.V. and Kohnke, C.S. (1998). Assessment of university foodservice employee job satisfaction and strategy formulation for managerial practitioners. Journal of College \& University Food Service, 3(4), pp. 13-27.

Ismail, H.A.K., Coetzee, N., Du Toit, P., Rudolph, E.C., \& Joubert, Y.T. (2013). Towards gaining a competitive advantage: the relationship between burnout, job satisfaction, social support and mindfulness. Journal of Contemporary Management, 10(1), pp. 448 - 464.

Izvercian, M., Potra, S., \& Ivascu, L. (2016). Job satisfaction variables: A grounded theory approach. Procedia-Social and Behavioral Sciences, 221, pp. 86-94.

Jackson, E., Schwab, R. L., \& Schuler, R. S. (1986).Toward an understanding of the burnout phenomenon. Journal of Applied Psychology, 71, pp. 630-610.

Judge, T. A., Parker, S., Colbert, A. E., Heller, D., \& Ilies, R. (2001) Job satisfaction: a cross-cultural review, in: N. Anderson, D. S. Ones, H. K. Sinangil and C. Viswesvaran (eds) Handbook of Industrial, Work and Organizational Psychology, Vol. 2 (London: Sage), pp. $25-52$

Kanste, O., Kynga, H., \& Nikkila, J. (2007). The relationship between multidimensional leadership and burnout among nursing staff. Journal of Nursing Management, 15(7), pp. 731-739.

Kim, S. (2005). Gender difference in the job satisfaction of public employees: a study of Seoul metropolitan government, Korea. Sex Roles, 52(9/10), pp. 667-681.

Koustelios, A. (2001). Personal characteristics and job satisfaction of Greek teachers. Journal of Educational Management, 15(7), pp. 354-358.

Koustelios, A., Theodorakis, N., \& Goulimaris, D. (2004). Role ambiguity, role conflict and job satisfaction among physical education teachers in Greece. International Journal of Educational Management,18(2), pp. 87-92.

Krogstad, U., Hofoss, D., Veenstra, M., \& Hjortdahl, P. (2006). Predictors of job satisfaction among doctors, nurses and auxiliaries in Norwegian hospitals: relevance for micro unit culture. Human resources for health, 4(3). 
Lawler, E.E. (1990). High Involvement Management, Jossey-Bass, San Francisco, CA.

Lim, S. (2008). Job satisfaction of information technology worker in academic libraries. Library \& Information Science Research, 30(2), pp. $115-121$

Lin, F., St John, W., \& McVeigh, C. (2009). Burnout among hospital nurses in China. Journal of Nursing Management, 17(3), pp. 294-301.

Locke, E.A (1976). The nature and causes of job satisfaction, in Dunette, M D. (ed) Handbook of Industrial and organisation psychology. Chicago: RanMcNally.

Mantelou, E., Tzioti, M. C., Degleris, N. E., Solias, A., \& Karamberi, M. (2010, April). Job burnout, self-efficacy theory and job satisfaction in a sample of greek bank clerks. In Annals of general psychiatry, 9,1, pp. $1-1$

Maslach, C., \& Jackson, S.E. (1981). The measurement of experienced burnout. Journal of Organizational Behavior, 2(2), pp. 99-113.

Maslach, C., Schaufeli, W. B., \& Leiter, M. P. (2001). Job burnout. Annual Review of Psychology, 52(1), pp. 397-422.

Moreira, D.S., Magnago, R.F., Sakae, T.M., \& Magajewski, F.R. (2009). Prevalence of burnout syndrome in nursing staff in a large hospital in the south of Brazil. Cadernos de Sau de Publica, 25(7), pp. $1559-1568$.

Naftemporiki (2019). Biggest deal since 2008 reshapes U.S. banking landscape. Accessed 28-08-2020 from: https://www.naftemporiki.gr/finance/story/1442575/to-megaluterodeal-apo-to-2008-anamorfonei-to-trapeziko-topio-stis-ipa

Nirel, N., Shirom, A., \& Ismail, S. (2004). The relationship between job overload, burnout and job satisfaction, and the number of jobs of Israeli consultants [in Hebrew]. Harefuah, 143, pp. 779- 84.

Oplatka, I., \& Mimon, R. (2008). Women principals' conceptions of job satisfaction and dissatisfaction: an alternative view? International Journal of Leadership in Education, 11(2), pp. 135-153.

Ozyurt, A., Hayran, O., \& Sur, H. (2006). Predictors of burnout and job satisfaction among Turkish physicians. Journal of the Association of Physicians, 99(3), pp. 161-169.

Pallant, J. (2010). SPSS survival manual. Maidenhead: Open University Press.

Passas, D., \& Saliaris, V. (2014). Greece, in Jan Putnis, The Banking Regulation Review, Law Business Research, Fifth Edition pp. 362-385.
Pereda-Torales, L., Celedonio, F.G.M., Vasquez, M.T.H., \& Yanez Zamora, M.I. (2009). Burnout syndrome in medical practitioners and paramedic personal. Salud Mental, 32(5), pp. 399-404.

Rayton, B. A. (2006). Examining the interconnection of job satisfaction and organizational commitment: An application of the bivariate probit model. International Journal of Human Resource Management, 17(1), pp. 139-154.

Saari, L.M., \& Judge, T.A. (2004). Employee Attitudes And Job Satisfaction. Human Resource Management, 43(4), pp. 395-407.

Saleem, H. (2015). The impact of leadership styles on job satisfaction and mediating role of perceived organizational politics. Procedia-Social and Behavioral Sciences, 172, pp. 563-569.

Schaufeli, W.B., \& Enzmann, D. (1998). The burnout companion to study and practice: a critical analysis. London: Taylor and Francis.

Schultz, P., \& Schultz, E. (1994). Psychology and Work today, 6th edn, New York: Mac Millan.

Spector, P. (2000). Industrial and organizational psychology, New York: John Wiley \& Sons.

Spector, P.E. (1997). Job Satisfaction: Application, Assessment, Causes, and Consequences, Sage, Thousand Oaks, CA.

SSQ Financial Group (2013). Reference document Burnout. Accessed 2812-2019 from: https://ssq.ca/sites/default/files/archives/ac/Chroniques_sante/Burn out.pdf.

Tavakol, M., \& Dennick, R. (2011). Making sense of Cronbach's alpha. International Journal of Medical Education, 2, pp. 53-55.

Tracey, J.B., \& Hinkin, T.R. (1996). How transformational leaders lead in the hospitality industry. International Journal of Hospitality Management, 15(2), pp. 165-176

Vargas, C., Canadas-De la Fuente, G.A., Aguayo, R., Fernandez-Castillo, R., \& de la Fuente, E.I. (2014). Which occupational risk factors are associated with burnout in nursing? A meta-analytic study. International Journal of Clinical Health Psychology, 14(1), pp. 28-38.

Wegge, J., Dick, R. V., Fisher, G. K., West, M. A., \& Dawson, J. F. (2006). A test of basic assumptions of Affective Events Theory (AET) in call centre work 1. British Journal of Management, 17(3), pp. 237254. 